\title{
THE DRAMATISATION OF 'ECO-TECHNOLOGIES' IN RECENT HIGH-RISE TOWERS
}

\author{
SANDRA KAJI-O'GRADY \\ Faculty of Design, Architecture and Building \\ University of Technology, Sydney \\ PO Box 123, Broadway, NSW 2007, Australia \\ sko@uts.edu.au
}

\begin{abstract}
Architects select, specify, organize, integrate and innovate specific technologies. In doing so, architecture also plays a dramatizing role in concealing or revealing the effects and operations of selected technologies. This paper addresses the ways in which the architecture of recent high-rise towers gives theatrical presence to so-called 'eco-technologies', as well as the ambitions and consequences of this dramatization. High-rise towers have become, as Russell argues 'the lab benches for sustainable technology innovation' (1 of 5). Major banks and corporations such as Commerzbank, Bank of America and even the Guangdong Tobacco Company, are choosing to invest in high-rise projects using a variety of emergent technologies to reduce their environmental impact and energy needs. The capital investment made by corporations in sustainable technologies in high-rise building is, at this stage, not financially recouped in reduced running costs and is made with other ambitions that necessitate making those technologies visible in the broader marketplace. This paper will examine the ways in ecotechnologies are given a dramatic presence in the high-rise tower independently of requirements for installation and operation and then put to market advantage through strategic media campaigns. In doing, so the paper more broadly examines the transfer of technology from 'thing' to architectural form to discursive carrier in the marketplace.
\end{abstract}

Keywords: High-towers, eco-technologies.

\section{Introduction}

Rem Koolhaas proposes that the architectural role of the tower is reduced to an empty monumentalism, its sheer volume making it a memorial or billboard for its own creation, since economics, rather than architects, determine the form of tall buildings. The tower, he fumes, is 'a solipsism, celebrating only the fact of its disproportionate existence, the shamelessness of its own process of creation'. The argument is a familiar one. Tafuri argued that the tower serves a 'self-proclaiming, publicity function' for capitalism (457). Pertuiset claims that the success of the office tower in representing corporations lies in its distinctiveness from others of its type, leading to the paradox that 'the office building as a semantically neutral type is yet most likely to be dressed in a seductive image' (87). Or as Clarke states, the skyscraper 'is sunk capital which must have credentials in the marketplace' (54). 
A more nuanced view is needed to recognize the entanglement of technology and its representation in high-rise building. The raft of technologies needed to achieve height have been used to convey a range of potential meanings that may confirm corporate capital, but have also the potential to convey philanthropic benevolence, intransigence, political agility, patriotism, a belief in progress, nostalgia, civic pride, romance, pragmatism, religious belief, etc. Following the events of September 11, 2001 the cultural meanings ascribed to the high-rise tower have again been much debated and there has been, contrary to those who declared the death of the high-rise, a resurgence of tall building developments and public discussion about them. 'Tall buildings' were the subject of an exhibition at MOMA in 2003 at which it was evident that the building type was the focus of renewed experimentation in urbanism, particularly in new cities in the developing world, as well as in form making using digital techniques and manufacturing. Where the drive to go higher and higher has led to the high-rise being the site of the most intense innovation of hard technologies, more recently the high-rise has also been used for testing new forms of workplace organization, hybrid programming and construction financing. Most significantly, high-rise towers have become, as Russell argues 'the lab benches for sustainable technology innovation' (1 of 5). This paper is focused on the relationship between the set of specific technologies directed at environmental sustainability and their representation in the marketplace through current projects including: Turning Torso by Calatrava in Malmo, Sweden; Editt Tower, by Hamzah and Yeang in Singapore, the COR tower in Miami and One Byrant Park by Cook and Fox in New York. While attending to one set of technologies and a small number of examples, broader conclusions about the architectural representation of technology will be drawn.

\section{Technological innovations and the high-rise tower}

It is worth first considering the high-rise tower through the incremental history of technological innovations that have made them possible. Buildings over six stories were rare until the $19^{\text {th }}$ century, largely because water pressure was insufficient to supply running water over about 15 metres. The advent of Otis' elevator and the introduction of steel-frame construction are the most obvious innovations of the early twentieth century making it possible for buildings of greater heights. The geared high-speed, electric elevator evolved only after the early $1880 \mathrm{~s}$ when cities were electrified. Air-conditioning for heating and cooling was the next necessary innovation. The first paper mill was air conditioned in 1906, but its uptake in commercial buildings until after the 1930s when coil systems reduced the size of ducts and deep interior space became rentable.

Subsequent technologies that have enabled increasing heights include: technologies of waste management and services comprised of tanks, exhausts, pumps and generators; technologies of fire fighting and sprinkling; and technologies of information and telecommunications that make possible the generic open plan through their reticulation in the computer floor or the false ceiling. Envelope technologies of curtain walling along with technologies of cleaning that include cherry pickers, cradle systems and telescopic equipment are also crucial. Surveillance, security and even pre-emptive defence technologies have more recently become paramount.

As heights increase, levels of vibration under the action of wind and seismic disturbance become more prevalent and can provoke vertigo and nausea (Kareem, Kijewski and Tamura: 1-2). Advances in height are often accompanied by increased structural flexibility, and the most recent generation of tall buildings research has been devoted in part to the mitigation of windinduced movement through passive technologies of aerodynamic tailoring, stiffening and energy dissipation, as well as active auxiliary dampening systems that may also include rotor, jet and aerodynamic appendages that generate a control force to reduce wind-force coefficient (Kareem, Kijewski and Tamura: 40-41).

\section{Different forms of technology}

Without these interrelated technologies the contemporary high-rise building is not possible. Yet, the high-rise depends upon additional technologies that go unrecognized if technology is only considered as an entity or thing and not, as it also is, effect, metaphor, sets of practices and processes, economic engine and historical subject. As Marchand observes in relation to the motorcar, its technological reach also includes 'the network of gas stations, highways, neon signs, parking lots, and all the altered habits and perceptions that arise out of the existence of the car-the ground, in other word, of the automobile. (Marchand 1990, 248) Larry Ford notes that the production of the tower is the convergence not only of industrial technologies, but also cultural values, economic organization, skilled labour and governmental policies (180). The 
tower requires large corporations for its commissioning and occupation, zoning laws that encourage higher buildings and policies that allow the consolidation of land. The organization and application of hard technologies and the determination of floor plans and heights is regulated by a set of techniques and soft technologies of information management, financial modelling and statistical analysis, property valuation and market prediction that are new to the twentieth century.

Michel Foucault usefully distinguishes between four kinds of technologies: technologies of the self, by which we know and look after ourselves; technologies of production with which we interact with the material world; technologies of sign systems, through which we mediate culturally; and technologies of power, by which societies discipline and organize individuals within them. These are not watertight categories into which specific technologies can be placed rather, each technology takes effect in all four arenas. Writing, for example, is a technology. It calls for the use of tools and other equipment, is governed by rules and processes, and enhances and transforms the self and society. Technologies of writing and seeing have been interiorised to the point that we forget them, but both of these technologies mediate all other technologies. The wind-turbines used in the COR-tower in Miami, for example, are mediated by design technologies that shape form and give presence through motion or visibility. These are in turn mediated by technologies of visualisation such as photography and $3 \mathrm{~d}$ computer modelling, paired with marketing techniques that influence community perception and reception.

\section{Technology transfer and architecture}

The revealing or concealing of certain technologies in tower design, such as the wind turbines in the COR-tower, is an act of transference and transformation of economic, political and architectural consequence. In using the term 'technology transfer', it must be admitted that this use departs from its most common application in management studies where it refers to how new technologies are brought to markets across nations or from research institutions such as Universities, to corporations and governments (Bozeman 627-655) The abundant literature in this area is concerned with the effectiveness of technology transfer, with the conditions and agents of failure and success that surround the technology and are independent of its actual attributes. The cultural meanings given to technology are also regarded as significant in technology transfer, but the movement from technology as an entity to the raft of cultural meanings given to its application is largely understudied and left to other branches of the humanities. Also understudied is the transfer of technologies and techniques developed in one field or industry to another and the ways in which these technologies are represented in the new field. It is these ways of thinking about transfer through the vehicle of architecture that is of interest here.

Architecture imports technologies developed in other industries and disciplines such as space exploration, food preservation, gaming and mapping. These adoptions and adaptations are not always apparent, and may, indeed, be intentionally concealed. When technologies from outside of architecture are engaged as a potential for design expression-for representative potential in addition to operational value-different approaches are taken. Rüdiger Lainer and Ina Wagner, distinguish four ways in which architecture gives representation to technologies from outside the discipline (145-146). The first is to present technical objects and exhibit the technologies, functions and achievements they build upon. Early modernist architecture and large-scale technical objects such as power stations that combine utility with its symbolic enhancement are situated in this category (146). The second approach they identify is that of making technical elements and processes visible, as in Richard Roger's Lloyd's building with its exteriorization of services pipes and shafts, elevators (147). The third approach lies in intensifying the effects and qualities of an object. This approach to architecture "may increase a functional aspect of the building. It also may augment representative elements and have strong dramaturgical effects" (148). Arguably, the Lloyd's building does this too. Fourthly, they identify space as mise-enscéne of technology. In this category, they locate architecture which, with the support of programmable lighting and multi-media projections, mobile furniture and rapid changes of scenery, creates 'spaces within space'.

Lainer and Wagner's short essay is a useful departure point, but when considering the high-rise tower, it becomes apparent that all of their four approaches to 'narrating' technology are at work. These are large-scale technical objects wherein some, or all, of the enabling technologies are made visible or dramatized. In the theoretical discussions of theatricality in other cultural forms, dramatization is thought to support an experience distinct from the physical object with the viewer aware of exaggeration. Theatricality in the cultural arena is connected to exaggeration, illusion and a fictional framing that allows the spectator to recognize both resemblance and 
deviation. The theatrical demonstration or concealment of its technologies is not uniformly recognized by all audiences in the case of the high-rise tower. Both the use and the representation of technologies, especially of recent eco-technologies, as will be demonstrated is, in parallel, framed by extensive media coverage that directs perception of the building.

\section{Eco-Towers}

Turning Torso in Malmo, Sweden is a good example of the theatrical representation of a structural technology in architectural form whilst environmental technologies remain invisible. Completed in 2005, it was designed by Calatrava and has been much imitated with similar turning towers including RMJM's City Palace in Moscow and SOM's Infinity Tower in Dubai. Calatrava's tower is a 54-storey building made up of nine cubes that twist towards the city's waterfront. The structural challenges of Turning Torso are the theatrical gesture of technology for this building, yet unlike other Calatrava projects, the actual structural solution and the apparent structural dynamic are not congruent. Each floor consists of a square section around the core and a triangular part supported by an external steel structure. This core is stiffened by the Torso's exoskeleton, which is effectively a steel truss erected on the outside of the building with the same clockwise rotation as the tower itself. The building looks like the structure is twisted but this is not the case.

Turning Torso has an environmental agenda. Kitchen waste, for example, is transported to a collection tank where it is then piped to a decomposition plant producing biogas. There is diode lighting in common corridors. Its energy efficient envelope has passed several laboratory tests concerning air and water sealing and heat insulation according to stringent Swedish standards. None of these technologies are signified in the visual appearance of the building and their inclusion in the media releases is subordinate to the celebration of the twisted form. By contrast, the 'eco-technologies' of wind turbines, photovoltaics, solar hot water generation and a hyper efficient structural system are highly elaborated for visual consumption in the COR tower in Miami, currently under construction. Designed by Oppenheim Architecture, with energy consultant Buro Happold and structural engineer Ysreal Seinuk, the 25-story COR tower is being touted as the first sustainable mixed-use apartment complex in Florida. Each residential unit will include Energy Star appliances, recycled glass tile flooring, and bamboo-lined hallways. Its exoskeleton simultaneously provides structure, thermal mass for insulation, shading for natural cooling, enclosure for terraces and armatures for turbines. The revolving motion of the turbines at the top of the building is underscored by the repetition of the circular motif across the whole of the façade. The building is being promoted pre-sale on sites such inhabitat.com, a weblog advocating sustainable design; and treehugger.com, which describes itself as the "leading media outlet dedicated to driving sustainability mainstream."

Editt Tower by TR Hamzah and Yeang, Singapore is even more explicit in its incorporation of ecologically sustainable technologies. The project won a 1998 competition for Ecological Design in the Tropics and is co-sponsored by the Urban Redevelopment Authority and the National University of Singapore for an urban site in which the natural ecosystem has been erased. The project integrates green space to human-use area in the ratio of 1:2. The organic spaces are intended also to ramp up from the street level to the top of the building, effectively integrating its 26 stories into the surface landscape. Plants incorporated in the building project do not compete with indigenous species and this point is reiterated in all promotional material. The building will have over $55 \%$ water self-sufficiency based on collection of rainwater and water reuse, and is designed to achieve almost $40 \%$ energy self-sufficiency through a system of solar panels. Sewage will be reclaimed to fertilizer and built-in waste hoppers will drop separated waste streams to the basement to facilitate recycling. Architectural elements are designed to direct wind for ventilation and ceiling fans with water misters minimize refrigerant based air conditioning. These technologies are made visible-in addition to the planting, the naturally ventilated toilet areas are hung on the edges of the building and the water collection scallops along the side of the building, leading to media claims such as that made by Lepisto, that the building is a 'living breathing organism'. Other aspects, such as the mechanically jointed construction that addresses the potential life-cycle of the building and material reclamation, are not immediately apparent.

Designed by Cook and Fox Architects, One Bryant Park, New York City is a 50:50 joint venture between the Durst Organization and Bank of America who will occupy most of the 54-story building. Bank of America were the first financial services company to become a member of the EPA's Climate Leader Program and won the 2005 Corporate Climate Champion award from Clean Air-Cool Planet. The tower will be built largely from recycled and recyclable materials, incorporate a cogeneration electricity plant, capture and use all rainwater and wastewater and 
have a planted roof to reduce heat island effect. The most, or indeed only visible portion of the building where the 'green' strategies are visible is in facets of the curtain wall.

Given that the building is less evidently 'green' than Editt Tower, Bank of America have sought, and gained, considerable media coverage and high-level political support. In the media release for the building Governor Pataki lauds it as 'a shining example of how you can create jobs while also protecting the environment'. Publicity has focused on the intention to qualify for a LEEDS platinum rating, a first for a building of this scale. Joining the Bank of America as a corporation keen to announce its green credentials through architecture, is the Guangdong Tobacco Company with a proposed zero-energy tower in Guangdong, China designed by Skidmore Owings and Merrill. The 300 metre tall tower features integrated wind-turbines on two separate mechanical floors and a southern façade with louvers calibrated to automatically adjust to sun angle and intensity.

Guangdong's tower was reviewed by Deborah Snoonian in Architectural Record, and covered in the online Metropolis Magazine and Business Week as well as numerous 'green' websites such as the Energy Blog and jetsongreen. When it featured on the treehugger website, one anonymous respondent quipped: 'Well good luck on the solar power . . . the sun rarely shines through the pollution in Guangzhou. If it could run on smog power or cigarette fumes now that would be something!' Silas Chiow, director of China business development at SOM is less cynical, but in Business Week confessed that "I would be surprised if the Pearl River Tower was a $100 \%$ zero-energy building upon completion, because that would be 10 times the cost of a normal building that size."

\section{Conclusion}

For any developer of a high-rise tower using technologies that alleviate environmental impact, potential long-term savings on energy costs and workplace productivity do not currently offset the higher capital investment. Perceived market benefits for corporations in using sustainable design technologies appear to be a factor in their uptake, and these can only accrue if the broadest audience is aware of their use. The range of technologies used in the new wave of sustainable high-rise buildings varies greatly in their potential for visibility and dramatization. Eco-paint, for example, looks much like any other paint, whereas planted walls and roofs, channels of flowing water and rotating turbines are readily transferred into architectural design and given dramatic presence.

These technologies project a different fiction to that of earlier high-rise towers wherein the expression of technologies is brought to bear upon the landscape of competitive capitalism and appeals to notions of technological prowess and mastery over natural forces of gravity, wind and sun. Eco-technologies are being used in high-rise towers to project an image of civic and corporate concern and responsiveness to place through appealing to 'nature'. Cook and Fox, for example, claim that One Bryant Park has 'the dynamic and crystalline structure of forms encountered in the natural world'. Emphasis is on the potential of achieving metaphoric associations through integrating environmental technologies with new technologies of structure and envelope. Editt Tower is presented, quite literally as a vertical garden. The dramatization of technologies in the recent wave of high-rise buildings purporting to achieve sustainable results presents these technologies as benign and working with, not against, natural forces, both in architectural form and in associated publicity. Technological transfer is effected both in operation and representation.

\section{References}

Bank of America. Press Release: Bank of America and the Durst Organization Break Ground on the Bank of America Tower at One Bryant Park in New York City, August 2, 2004 <http://bankofamerica.mediaroom.com/index.php?s=press_releases\&item=4405>

Bozeman, Barry. "Technology Transfer and public policy: a review of research and theory." Research Policy 29 (2000): 627-655.

Business Week. "China's Ultra-Green Pearl River Tower." Businessweek.com May 14, 2007. $<$ http://www.businessweek.com/globalbiz/content/may2007/gb20070514_772812.htm?chan=i nnovation_architecture_building+innovation>

Clark, Paul Walter. "The Economic Currency of Architectural Aesthetics." Threshold 4 (1988): 50-61. 
Féral, Josette. "Performance and Theatricality: The Subject Demystified." Modern Drama 25 (1982): 170-81.

Ford, Larry. "Reading the Skylines of America." Geographical Review 82, 2 (April 1992): 180200.

Feenberg, Andrew. Critical Theory of Technology. Oxford University Press: New York, 1991.

Foucault, Michel. Technologies of the Self: A Seminar with Michel Foucault, Martin, L. H., Gutman, $\mathrm{H}$ and Hutton, P. H., eds., University of Massachussets Press: Amherst, 1988.

Koolhaas, Rem. "The Bloke Alone." art-omma 7 (Spring 2002) <http://www.artomma.org/NEW/past_issues/theory/07_The\%20Bloke\%20Alone\%20by\%20Rem\%20Koolhaa s.htm>

Kareem, A., Kijewski, T. and Tamura, Y. "Mitigation of Motions of Tall Buildings with Specific Examples of Recent Applications." Wind and Structures 2, 3 (1999): 201-251.

Lainer, R. and Wagner, I. "Silent Architecture-Narrative Technology." Digital Creativity 11, 3 (2000): 144-155.

Lambot, I. and Davis, C. Commerzbank Frankfurt: Prototype for an Ecological Highrise. London: Watermark Publications, 1997.

Lepik, Andres. Skyscrapers. Prestel: New York, 2004.

Lepisto, Christine. "The Editt Tower by Dr Ken Yeang". (17 April, 2005) Treehugger.com <http://www.treehugger.com/files/2005/04/the_editt_tower_1.php> accessed 30 June 2007.

Marchand, Philip. Marshall McLuhan: The Medium and the Messenger. Vintage Books: Toronto, 1990.

Nordensen, Guy and Riley, Terrence. Tall Buildings. New York: MOMA, 2003.

Ong, Walter, Orality and Literacy: The Technologizing of the Word. Routledge: London, 1982.

Pertuiset, Nicole. "The Lloyds Headquarter: Imagery Takes Command." Thomas A. Dutton, ed. Icons of Late Capitalism: Corporations and Their Architecture. Miami University: Oxford, Ohio, 1986.

Russell, James. "Do skyscrapers still make sense? Revived downtowns and new business models spur tall-building innovation." Architectural Record.com, 2004 <http://archrecord.construction.com/innovation/2_Features/0411SkyscraperSense.asp>, $\quad 5$ pages.

Deborah Snoonian, "SOM aims to build a zero-energy office tower in Guangdong." Architectural Record.com <http://archrecord.construction.com/ar_china/news_0604som.asp. 2006>

Tafuri, Manfredo. "The Disenchanted Mountain." The American City. G. Ciucci, F. Dalco, M. Maniera-Elia, and M. Tafuri, eds. Cambridge: The MIT Press, 1979.

Treehugger. "Zero energy tower could rise in Guangdong China." (19 April 2006) Treehugger.com <http://www.treehugger.com/files/2006/04/zeroenergy_towe.php> accessed 1 July 2007. 